\title{
Evaluation of Yeast and Lactic Acid Bacteria Starter Cultures for the Production of Rice Injera
}

\author{
Hassen $\mathrm{Y}^{1 *}$, Mukisa $\mathrm{IM}^{2}$, Kurabachew $\mathrm{H}^{1}$ and Desalegn $\mathrm{BB}^{1}$ \\ ${ }^{1}$ School of Nutrition, Food Science and Technology, College of Agriculture, Hawassa University, Hawassa, Ethiopia \\ ${ }^{2}$ Department of Food Technology and Nutrition, Makerere University, Kampala, Uganda
}

\begin{abstract}
Injera is a yeast-risen flat-bread with a unique, slightly spongy texture. It is a national staple in Ethiopia that is eaten daily in virtually every household. Despite the fact that injera is a favorite staple food, starters have not been evaluated for the production of rice-based injera. Combination of starter cultures of lactic acid (Lactobacillus plantarum, Lactobacillus fermentum) and yeast (Saccharomyces cerevisiae) and irsho (back slopping) were used to ferment rice batter during $96 \mathrm{~h}$. Changes in $\mathrm{pH}$, titratable acidity (TA) and microbial count were analyzed at $6 \mathrm{~h}$ intervals and consumer acceptability was done at $24 \mathrm{~h}$ and $48 \mathrm{~h}$. LAB starters and their co-cultures yeast decreased pH from 6.35 to 4.5 and increased titratable acidity from $0.33 \%$ to $0.95 \%$ (lactic acid w/w ) within 18-24 $\mathrm{h}$ while in the spontaneous fermentation with traditional irsho it took $48 \mathrm{~h}-54 \mathrm{~h}$ to attain $\mathrm{pH}$ and titratable acidity value of $0.38 \%$ and $0.93 \%$, respectively. The number of lactic acid bacteria and yeast increased in all starter culture and naturally fermented rice batter with fermentation time. Rice injera prepared using combination of $L$. plantarum $+S$. cerevisiae starters were the most acceptable (score of $8.83=$ like extremely). Therefore, the $L$. plantarum $+S$. cerevisiae starter combination can be used for commercial production of acceptable rice injera.
\end{abstract}

Keywords: Rice injera; Lactobacillus plantarum; Lactobacillus fermentum; Saccharomyces cerevisiae

\section{Introduction}

Injera is the favorite staple food for majority of Ethiopians. It is a fermented, pancake-like, soft, sour, circular flatbread [1]. It is made from flour, water and a natural mixed starter culture called irsho. Irsho is a fluid saved from previously fermented dough. Injera can be produced from various cereals depending on availability and abundance of the cereals [2]. It can be made from teff (Eragrostis tef), wheat, barley, sorghum or maize, and combinations of some of these cereals [3]. Fermentation of batter for injera making relies on chance inoculation or back slopping. This results in a product of unpredictable and inconsistent quality [4]. In order to maintain and sustain African indigenous fermented foods and beverages, controlled fermentation is strongly recommended [5-9]. The use of suitable starter cultures improves the fermentation process, facilitates the control over the initial phase of fermentation and the predictability of derivative products also reduces the organoleptic variations and the microbiological instability of African fermented food [4,10]. Controlled fermentation can be achieved by use of pure or mixed starter cultures with appropriate technology [11].

Lactic acid bacteria (LAB) and yeasts have been reported to be the predominant microorganisms in most of the African indigenous fermented foods [12]. Stable co-metabolism between LAB and yeasts is common in many foods, enabling the utilization of substances that are otherwise non-fermentable (for example starch) and thus increasing the microbial adaptability to complex food ecosystems [13]. Lactic acid bacteria $(\mathrm{LAB})$ and yeast are appreciated as starter cultures and for their health benefits [14].

Lactobacillus plantarum, Lactobacillus brevis, and Lactobacillus fermentum are regarded as the predominant species in the fermentation of teff, with Lactobacillus plantarum being the most dominant [15-17]. Moroni et al. [18] in their study on biodiversity of lactic acid bacteria and yeasts in spontaneously-fermented buckwheat and teff sourdoughs found that LAB (Lactobacillus pontis) and yeasts (Saccharomyces cerevisiae and Candida glabrata) dominated teff sourdoughs. Askal and
Kebede [19] found that LAB such as P. pentosaceus, L. fermentum and yeasts including $C$. humilis, C. tropicalis $S$. cerevisiae and S. exiguous involved in the fermentation of teff. Hiwot et al. [20] reported the preparation of injera using instant pre-fermented flour that showed the possibility of industrializing injera preparation. So far, no research has been done on the development of starter cultures for rice batter fermentation to prepare rice injera, a product which is getting huge acceptance by the Ethiopian community. Traditionally, rice batter fermentation uses irsho from the previous fermented batter to initiate new batches (back slopping). Homemakers, who bake injera every 2-3 days know the usefulness of this traditional starter culture. However, failures do occur in traditional fermentations leading to inconsistencies in quality of injera. Despite the importance of rice injera and challenges with inconsistencies in fermentations, starters cultures have previously not been evaluated for its production. Thus, there is a need to upgrade the quality of injera and bring desirable changes. This study was, therefore, carried out to evaluate the contribution of different LAB ( $L$. fermentum and L. plantarum) and yeast (S. cerevisiae) starter culture combinations in rice injera batter fermentation.

\section{Materials and Methods}

\section{Preparation of the starter cultures}

Two strains of lactic acid bacteria (L. fermentum M64 and $L$. Plantarum K72) and yeast strain (Saccharomyces cerevisiae M17) isolated from teff injera fermentation were used in this study. These strains were kindly provided by the Department of Biology, School

*Corresponding author: Yassin Hassen, School of Nutrition, Food Science and Technology, College of Agriculture, Hawassa University, PO Box 05, Hawassa, Ethiopia, Tel: +251-462205311; E-mail: yassin.hassen@gmail.com

Received February 06, 2018; Accepted February 27, 2018; Published March 06 2018

Citation: Hassen Y, Mukisa IM, Kurabachew H, Desalegn BB (2018) Evaluation of Yeast and Lactic Acid Bacteria Starter Cultures for the Production of Rice Injera. J Food Process Technol 9: 721. doi: 10.4172/2157-7110.1000721

Copyright: $\odot 2018$ Hassen $Y$, et al. This is an open-access article distributed unde the terms of the Creative Commons Attribution License, which permits unrestricted use, distribution, and reproduction in any medium, provided the original author and source are credited. 
Citation: Hassen Y, Mukisa IM, Kurabachew H, Desalegn BB (2018) Evaluation of Yeast and Lactic Acid Bacteria Starter Cultures for the Production of Rice Injera. J Food Process Technol 9: 721. doi: 10.4172/2157-7110.1000721

Page 2 of 5

of Nutrition, Food Science and Technology, Hawassa University. The Saccharomyces cerevisiae strain was cultured on yeast extract dextrose peptone (YEPD) agar at $30^{\circ} \mathrm{C}$ for $48 \mathrm{~h}$ and then successively subcultured in YEPD broth at $30^{\circ} \mathrm{C}$ for $24 \mathrm{~h}$. Lactobacillus plantarum and L. fermentum were cultured at $37^{\circ} \mathrm{C}$ for $48 \mathrm{~h}$ on Man-Rogosa-Sharpe (MRS) agar followed by two successive rounds of sub-culturing in MRS broth with incubation at $37^{\circ} \mathrm{C}$ for $24 \mathrm{~h}$ and $16 \mathrm{~h}$, respectively. Yeast and LAB strains were each harvested by centrifugation at $4000 \times \mathrm{g}$ for $20 \mathrm{~min}$ and pellets were added into batter prior to fermentation in cell concentrations of $10^{8} \mathrm{cfu} / \mathrm{g}$.

\section{Preparation of batter for rice injera}

Wheat flour was bought from Awassa Flour Factory (Hawassa, Ethiopia). Rice and maize grains were bought from the open market (Hawassa, Ethiopia) cleaned of dust and other foreign matter and ground into flour using a local Hammer mill. The milled flours were sieved and tightly packed in polyethylene bags till use. Composite flour was prepared by mixing the flours in a ratio of 10:2:1.5 (rice: maize: wheat). Batter for Injera preparation was made by mixing the composite flour with water in the proportions of $1: 2(\mathrm{w} / \mathrm{v})$ flour to water in $5 \mathrm{~L}$ plastic buckets.

\section{Fermentation of batter for rice injera}

For natural (spontaneous) fermentation, the batter was inoculated with $10 \%$ of previously fermented batter. In the controlled fermentation, cell concentrations of $10^{8} \mathrm{cfu} / \mathrm{g}$ of each starter culture i.e., L. plantarum, L. fermentum, S. cerevisiae was added into the batter. Mixed fermentation by $\mathrm{LAB}$ and yeast was initiated by using equal proportion of each pure strain. The batter samples were fermented in triplicate at room temperature. Batter samples were withdrawn at $0 \mathrm{~h}, 6$ $\mathrm{h}$ and $96 \mathrm{~h}$ of fermentation, for determination of microbial counts, $\mathrm{pH}$ and titratable acidity [21].

\section{Preparation of rice injera from the cultured rice batter}

The cultured batters fermented for $24 \mathrm{~h}$ and $48 \mathrm{~h}$ were baked using an electric Mitad (Electric-Clay plate, made in Ethiopia) to produce Injera. Prior to baking, $5 \mathrm{~g}$ (or one tea spoon) of baking powder (sodium bicarbonate) was added to about $500 \mathrm{ml}$ of the fermented batter to make one injera pan cake. The batter was poured in a circular pattern on the Mitad, covered, and baked for 2 minutes. The baked injera was left to cool for $2 \mathrm{~h}$ at room temperature. Then after it was cut into triangular pieces and presented in triplicate for sensory evaluation.

\section{Consumer acceptability test}

The effect of fermentation time ( $24 \mathrm{~h}$ and $48 \mathrm{~h}$ ), starter cultures (LAB and yeast vs irsho - traditional starter culture) on sensory acceptability were evaluated by using an untrained panel $(n=30)$. A 9-point hedonic scale (9="Like extremely"; 8="Like very much"; $7=$ "Like moderately"; 6="Like slightly"; 5="Neither like nor dislike"; 4="Dislike slightly"; 3="Dislike moderately"; 2="Dislike very much"; $1=$ "Dislike extremely") was used to score the level of acceptance of the different attributes of rice injera. The rice injera samples without sauce (wot) were presented on identical serving trays and coded with three-digit random numbers. The order of sample presentation was randomized. Potable water held at room temperature was served for cleansing the palate before and between testing of injera samples. An empty covered beaker was provided for the purposes of expectoration.

\section{Statistical analysis}

Means \pm standard deviations were calculated from three independent replicates. The data were subjected to analysis of variance (ANOVA) using SAS software (version 9.0, Addinsoft, Paris, France). Significance was set at $\mathrm{p}<0.05$.

\section{Results}

\section{Enumeration of $\mathrm{LAB}$ and yeast in rice injera batter fermentation}

In controlled fermentations, the cell counts of LAB and S. cerevisiae increased from 5.09-8.45 $\mathrm{log} \mathrm{cfu} \mathrm{g}^{-1}$ and 4.11-7.5 $\mathrm{log} \mathrm{cfu} \mathrm{g}^{-1}$, respectively" In naturally fermented rice batter, LAB counts increased from $5.08 \mathrm{log}$ $\mathrm{cfu} \mathrm{g}^{-1}$ to $8.30 \log _{\mathrm{cfu} \mathrm{g}}{ }^{-1}$ after $48 \mathrm{~h}$ while the yeast counts increased from $4.1 \log \mathrm{cfu} \mathrm{g}^{-1}$ to $7.20 \mathrm{log}_{\mathrm{cfu} \mathrm{g}}{ }^{-1}$ in $24 \mathrm{~h}-48 \mathrm{~h}$ (Figures 1 and 2).

\section{Changes in $\mathrm{pH}$ and titratable acidity during rice batter fermentation}

The changes in $\mathrm{pH}$ of rice injera batter fermentation are shown in Figures 3 and 4. LAB starters (L. plantarum and L. fermentum and their co-cultures $S$. cerevisiae decreased $\mathrm{pH}$ from 6.35 to 4.5 and increased titratable acidity from $0.33 \%$ to $0.95 \%$ (lactic acid w/w) within $18 \mathrm{~h}-24$ $\mathrm{h}$. The natural fermentation took $48 \mathrm{~h}-54 \mathrm{~h}$ to attain a $\mathrm{pH}$ and titratable acidity of $0.38 \%$ and $0.93 \%$, respectively.

\section{Effects of LAB and yeast starters on consumer acceptability of rice injera}

Table 1 shows the effect of starter culture and fermentation time

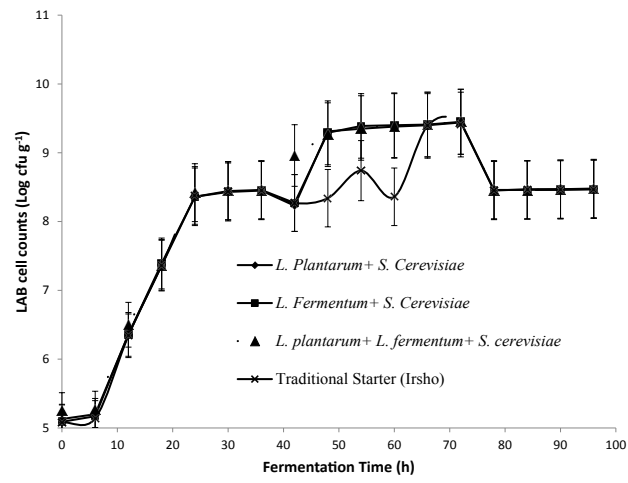

Figure 1: Changes in $L A B$ counts during fermentation of rice batter inoculated with starters and irsho (back slopping). Error bars show standard deviations of three independent fermentations.

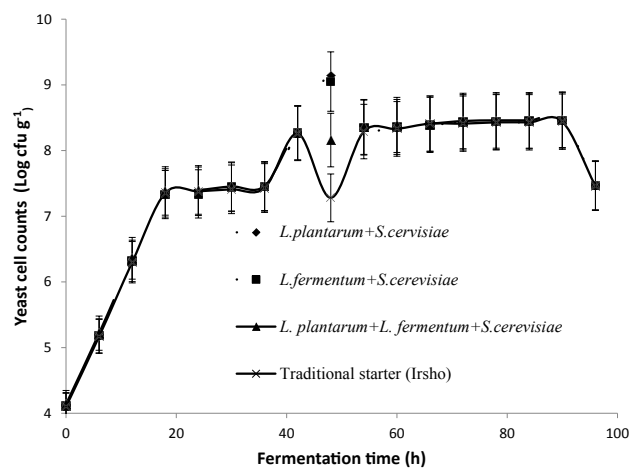

Figure 2: Yeast counts during fermentation of rice batter inoculated with starters and irsho (back slopping). Error bars show standard deviations of three independent fermentations. 


\begin{tabular}{|c|c|c|c|c|c|c|}
\hline Starter Combinations & Time & Appearance & Taste & Aroma & Mouth feel & Overall acceptability \\
\hline Irsho & 24 & $7.21 \pm 0.85^{\mathrm{hi}}$ & $6.80 \pm 1.82^{\mathrm{hi}}$ & $7.09 \pm 1.38^{\mathrm{fg}}$ & $7.28 \pm 1.08^{e}$ & $7.40 \pm 0.78^{c}$ \\
\hline L. plantarum + S. cerevisiae & 24 & $7.51 \pm 1.24^{\text {gh }}$ & $7.61 \pm 1.22^{\mathrm{ef}}$ & $8.67 \pm 0.97^{\text {cde }}$ & $7.33 \pm 1.47^{\mathrm{cd}}$ & $7.83 \pm 1.20^{\mathrm{cb}}$ \\
\hline L. fermentum + S. cerevisiae & 24 & $8.20 \pm 0.91^{\mathrm{abcd}}$ & $7.93 \pm 0.93^{d}$ & $7.60 \pm 1.36^{\mathrm{de}}$ & $8.00 \pm 1.04^{a}$ & $8.27 \pm 0.78 a b$ \\
\hline L. plantarum $+S$. cerevisiae $+L$. fermentum & 24 & $8.27 \pm 0.82^{\mathrm{abcd}}$ & $8.03 \pm 0.95^{\mathrm{bcd}}$ & $7.77 \pm 1.39^{\text {bcde }}$ & $8.10 \pm 1.05^{\mathrm{a}}$ & $8.33 \pm 0.79^{\mathrm{bc}}$ \\
\hline Irsho & 48 & $7.64 \pm 0.84^{\mathrm{fg}}$ & $7.32 \pm 0.88^{\mathrm{fg}}$ & $7.44 \pm 1.11^{\text {ef }}$ & $7.20 \pm 1.72^{f}$ & $7.86 \pm 0.92^{\mathrm{cb}}$ \\
\hline L. plantarum + S. cerevisiae & 48 & $7.53 \pm 1.26^{g}$ & $7.62 \pm 1.23^{\text {ef }}$ & $7.67 \pm 0.97^{\text {cde }}$ & $7.34 \pm 1.48^{c}$ & $8.83 \pm 1.22^{\mathrm{a}}$ \\
\hline L. fermentum + S. cerevisiae & 48 & $8.20 \pm 0.91^{\mathrm{abcd}}$ & $7.93 \pm 0.93^{\mathrm{d}}$ & $7.60 \pm 1.36^{\mathrm{de}}$ & $8.00 \pm 1.04^{\mathrm{ab}}$ & $8.27 \pm 0.78^{\text {bcd }}$ \\
\hline L. plantarum $+S$. cerevisiae + L. fermentum & 48 & $8.27 \pm 0.82^{\mathrm{abcd}}$ & $8.03 \pm 0.95^{\mathrm{bcd}}$ & $7.77 \pm 1.39^{\text {bcde }}$ & $8.10 \pm 1.05^{\mathrm{a}}$ & $8.33 \pm 0.79^{a b}$ \\
\hline
\end{tabular}

Values are means \pm standard deviations of three independent fermentations (number of panelists $=30$ ). Values in the same column with similar superscripts (a, b. $\mathrm{c}$ and d) are not significantly different at 5\% level of significance. The scores are interpreted as follows: 9 : Like extremely; 8: Like very much; 7: Like moderately; 6 : Like slightly; 5: Neither like nor dislike; 4: Dislike slightly; 3: Dislike moderately; 2: Dislike very much; 1: Dislike extremely.

Table 1: Sensory acceptability scores of rice injera produced using different starter combinations.

on the acceptability of rice injera. Overall acceptability scores ranged from 7.40 (like moderately) to 8.83 (like extremely). Starter cultures and fermentation time significantly $(\mathrm{p}<0.05)$ affected consumer acceptability. Rice injera produced using a combination of $L$. plantarum + S. cerevisiae received the highest overall acceptability score after 48 $\mathrm{h}$ of fermentation although this was not significantly different for the other LAB/and yeast starter culture combinations. Rice injera prepared from $L$. plantarum + S. cerevisiae starters that was fermented for 48 $\mathrm{h}$ scored the highest value 8.83 (like extremely) while injera prepared with Irsho (control) scored 7.40 (like moderately) $(\mathrm{p}<0.05)$. LAB and yeast starter culture combinations also produced rice injera with better quality. Rice injera produced using traditional starter Irsho received significantly $(\mathrm{p}<0.05)$ lower acceptability scores than rice injera produced with all combinations of LAB and yeast and baked after 24 and $48 \mathrm{~h}$ of fermentation (Table 1 ).

\section{Discussion}

\section{Changes in LAB and yeast cell counts during rice injera batter fermentation}

All microbial genera are not of equal importance in fermentation [22], therefore candidate isolates for starter culture development have to be evaluated for their contribution during fermentation. In the present study, the numbers of LAB and yeast increased because they are predominant microorganism in the rice batter. Increment in counts of LAB (5.08 to $8.3 \log \mathrm{cfu} \mathrm{g}^{-1}$ ) and yeast ( 4.1 to $7.2 \mathrm{log} \mathrm{cfu} \mathrm{g}^{-1}$ ) were recorded in spontaneously fermented rice batter in $48 \mathrm{~h}$. This is in line with Senait et al. [23] who reported yeast count of $8.49 \operatorname{log~g~}^{-1}$ within $48 \mathrm{~h}-96 \mathrm{~h}$ of fermentation of kocho with barely for injera preparation. In the same study, it was also found that yeast was the most dominant organism followed by lactic acid bacteria. In another study on yeast fermentation of teff, an average yeast count of $30 \mathrm{log} \mathrm{cfu} \mathrm{g}^{-1}$ of dough after $22 \mathrm{~h}-24 \mathrm{~h}$ of fermentation was observed [3].

Higher cell numbers of LAB (5-8.5 $\left.\log \mathrm{cfu} \mathrm{g}^{-1}\right)$ and yeast (4.11$\left.7.5 \log \mathrm{cfu} \mathrm{g}^{-1}\right)$ were observed during rice injera batter fermentation within $24 \mathrm{~h}$ (Figures 1 and 2) comparing to the control (spontaneous fermentation). This could be due to inoculating the batter with a higher initial load of actively growing starter cultures, which are also well adapted to rice batter fermentation. The increased number of LAB and yeasts with intensive exponential phase results in shortening the duration of rice batter fermentation. The rapid growth of LAB lowers $\mathrm{pH}$ and favors yeast growth during the subsequent batter fermentation stage [13].

The results obtained in the present study agree with results reported by Holzapfel [10] who indicated that fast growth of starter cultures results in fast acidification and flavor development thus contributing towards ensuring product safety.

\section{Changes in $\mathrm{pH}$ and titratable acidity during rice batter fermentation}

The reduction in $\mathrm{pH}$ and increment in acidity in the current study followed the same trend as the traditionally fermented foods such as atmit [24], borde [25] and Kunun-Zaki [6]. Furthermore, Mukisa [26] found that $\mathrm{LAB}$ and the $\mathrm{LAB} / \mathrm{S}$. cerevisiae co-culture decreased the $\mathrm{pH}$ of Obushera to less than 4 (3.5-3.8) within $12 \mathrm{~h}$ although L. fermentum only decreased it to 4.13 . While, the spontaneously fermented Obushera attained $\mathrm{pH}$ of 3.81 after $24 \mathrm{~h}$. In a similar study on the preparation of togwa, a Tanzanian fermented food Mugula et al. [27] reported that LAB lowered the $\mathrm{pH}$ from 5.87 to 3.24-3.49 and increased the titratable acidity from $0.08 \%$ to $0.30 \%-0.44 \%$ (w/w, lactic acid) in $24 \mathrm{~h}$ which is in agreement with the present study. In the present study, the reduction of $\mathrm{pH}$ and increment of titratable acidity of the fermented rice batter

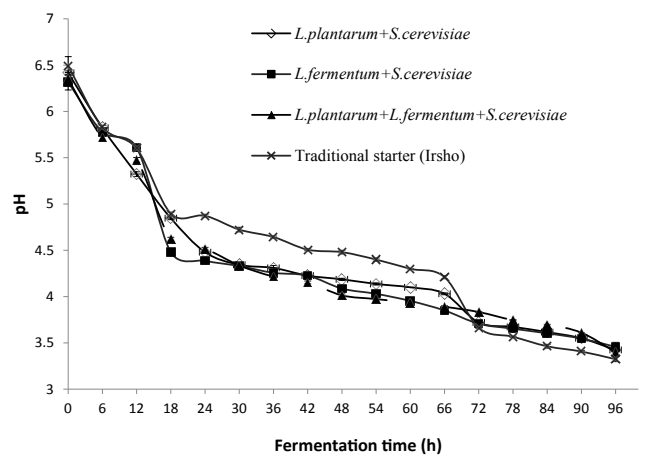

Figure 3: Changes in $\mathrm{pH}$ during fermentation of rice batter inoculated with starters and irsho (back slopping). Error bars show standard deviations of three independent fermentations.

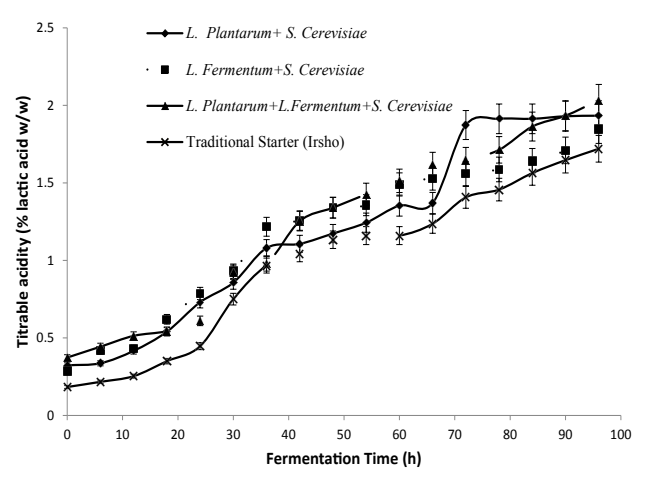

Figure 4: Changes in titratable acidity during fermentation of rice batter inoculated with starters and irsho (back slopping). Error bars show standard deviations of three independent fermentations. 
may be attributed to the production of organic acids by the microflora. Rapid drops in $\mathrm{pH}$ with corresponding increase in titratable acidity have been also reported in lactic acid fermentation of corn [28]. Similar accelerated acidification by LAB starters have also been reported in related studies [27-29]. Fast acidification to $\mathrm{pH}$ below 4.0 is desirable because low $\mathrm{pH}$ together with the un-dissociated acid inhibits spoilage bacteria, enteropathogens and Bacillus spp. thus contributing to preservation and safety $[12,22,30]$.

\section{Consumer acceptability of rice injera}

The combinations of LAB and yeast starter culture produced better quality rice injera compared to Injera produced by the traditional starter (irsho) with respect to appearance, taste, aroma, mouthful and overall acceptability after $24 \mathrm{~h}$ and $48 \mathrm{~h}$ of fermentation. Fast growth results in fast acidification and flavor development thus contributing towards shortening of processing time as well as ensuring product safety. The findings of the present study are in line with those of Glover et al. [11] who reported that starter culture combinations of LAB and yeasts produced better quality fermented products with more aroma compounds which improve flavor than single starters. The reason for the wide spread use of these organisms in food fermentation have been documented. The reasons include: their ability to produce desired flavor; formation of organic acids which reduce $\mathrm{pH}$ thus preventing growth of undesirable microorganisms; contributing to the development of the desired sensory qualities in the final product. Lactic acid bacteria are also used as 'natural' or 'selected' starters in food fermentations and exert antimicrobial effect as a result of different metabolic processes. Particularly, they have a key function in the development of the sensory and safety features of fermented food products.

The high overall acceptability scores of rice injera fermented with the LAB and $S$. cerevisiae starter cultures in the current study was due to co-metabolism of LAB and yeast which contributes towards development of characteristic flavor profiles of the products in which these two groups are involved. During cereal fermentations several volatile compounds are formed, which contribute to a complex blend of flavors in products. The presence of aromas such as: diacetyl, acetic acid and butyric acid make fermented cereal-based products more appetizing. Association of lactic acid bacteria and yeast during fermentation may also contribute metabolites, which could impart taste and flavor to fermented food.

The quality of rice injera depends on the type of raw materials, processing methods and processor practices and the starter culture used. Among the listed factors above, variety of the cereal used, and starter culture have huge impact on the sensory quality of rice injera. The flavor of food depends on the balance of volatile compounds that are inherently present in food or those produced during processing. A vast number of volatile compounds are synthesized and modulated by yeasts during fermentation. They significantly impart the overall quality of the product. These compounds include acids, higher alcohols, carbonyls, and esters. Previous studies on fermented cerealmix substrate from white and red sorghum, pearl millet and wheat have showed an increase in volatile compounds due to fermentation by yeasts and lactic acid bacteria. Similar to the current study it has been reported that yeast Saccharomyces cerevisiae contributes to flavour development while fermenting sorghum for gowe production.

\section{Conclusion}

In conclusion, the potential of LAB and yeast starter cultures to ferment rice injera batter and their effect on sensory acceptability was evaluated. Accelerated acidification of rice batter was achieved by using LAB starters of L. plantarum and L. fermentum co-cultured with $S$. cerevisiae. However, rice batter fermented by irsho showed slow activity. Accordingly, a combination of L. plantarum + S. cerevisiae can be used to produce acceptable rice injera. The information obtained from this study will serve as a basis for further investigations on process optimization and eventually to establish small scale rice injera production. Implementation of this culture in industrial production should improve the quality and uniformity of the final product as well as food safety by preserving typical sensory quality of the traditional fermented product and inhibiting the growth of undesirable microorganisms.

\section{References}

1. Bultosa G (2007) Physicochemical characteristics of grain and flour in 13 Tef. J Appl Sci Res 3: 2042-2051.

2. Taylor GB (2004) Paste and gel properties and in vitro digestibility of Tef [Eragrostis tef (Zucc.) Trotter] starch. Starch 56: 20-28.

3. Mogessie A (2006) A review on the microbiology of indigenous fermented foods and beverages of Ethiopia. Ethiopian J Biol Sci 5: 189-245.

4. Kimaryo VM, Massawe GA, Olasupo NA, Holzapfel WH (2000) The use of a starter culture on the fermentation of cassavafor the production of 'kivunde', a traditional Tanzanian food product. Int J Food Microbiol 56: 179-190.

5. Sadeghi A, Shahidi F, Mortazavi S, Mahallati M, Koocheki A, et al. (2009) Sourdough effect on reduction of Barbari bread staling. J Sci Technol Agricul Nat Res 13: 47-54.

6. Agarry O, Nkama I, Akoma O (2010) Production of Kunun zaki (A Nigerian fermented cereal beverage) using starter culture. Int Res J Microbiol 1: 18-25.

7. Kabeir B, Shuhaimi M, Muhammad K, Suraini A, Yazid A (2004) A nutritious media (Sudanese Cereal Thin Porridge) prepared by fermenting malted brown rice flour with Bifidobacterium Longum BB 536. Malaysian J Nut 10: 183-193.

8. Theodore I, Ikenebomeh J, Ahonkhai I (2007) Nutritional status of maize fermented meal by fortification with bambara-nut. African J Food Agricul Nutr Develop 7: 56-63.

9. Taiwo $O$ (2009) Physical and nutritive properties of fermented cereal foods African J Food Sci 3: 23-27.

10. Holzapfel WH (2002) Appropriate starter culture technologies for small-scale fermentation in developing countries. Int J Food Microbiol 75: 197-212.

11. Glover R, Sawadogo H, Diawara B, Jespersen L, Jakobsen M (2009) Utilization of Lactobacillus fermentum and Saccharomyces cerevisiae as starter cultures in the production of 'dolo'. J Appl Biol Sci 22: 1312-1319.

12. Steinkraus KH (1996) Handbook of indigenous fermented foods. Marcel Dekker Inc, New York, USA.

13. Gobbetti M (1998) The sourdough microflora: Interactions of lactic acid bacteria and yeasts. Trends Food Sci Tech 9: 267-274.

14. Tamime A (2002) Microbiology of starter cultures. Dairy Microbiology Handbook, John Wiley \& Sons Inc, New York, USA. pp: 261-366

15. Gashe BA (1985) Involvement of lactic acid bacteria in the fermentation of te (Eragrostis tef), an Ethiopian fermented food. J Food Sci 1: 800-801.

16. Lei V (2006) Probiotic potential of African fermented millet. Royal Veterinary and Agricultural University, Frederiksberg, Denmark.

17. Nigatu A (1998) Systematics of Lactobacillus and Pediococcus isolates from fermented Tef (Eragrostis tef) and Kocho (Ensete ventricosum) and microbiological status of baked products. Addis Ababa University, Addis Ababa Ethiopia.

18. Moroni AV, Arendt EK, Dal Bello F (2011) Biodiversity of lactic acid bacteria and yeasts in spontaneously-fermented buckwheat and teff sourdoughs. Food Microbiol 28: 497-502.

19. Askal D, Kebede A (2013) Isolation, characterization and identification of lactic acid bacteria and yeast involved in fermentation of Teff (EragrostisTef) Batter Int J Adv Res Biol Sci 1: 36-44.

20. Hiwot TA, Ashagrie ZW, Gulelat DH (2013) Preparation of injera from prefermented flour: Nutritional and sensory quality. Int J Sci Inno Disco 3: 165-175. 
Citation: Hassen Y, Mukisa IM, Kurabachew H, Desalegn BB (2018) Evaluation of Yeast and Lactic Acid Bacteria Starter Cultures for the Production of Rice Injera. J Food Process Technol 9: 721. doi: 10.4172/2157-7110.1000721

21. Oguntoyinbo FA (2008) Evaluation of diversity of Candida species isolated from fermented cassava during traditional small scale gari production in Nigeria. Food Control 19: 465-469.

22. Holzapfel WH (1997) Use of starter cultures in fermentation on a household scale. Food Control 8: 241-258.

23. Senait Z, Kelbessa U, Ayele N (1997) Microbiology of siljo fermentation. Ethiopian J Sci 18: 139-142.

24. Kelbessa U, Keshava N (1998) Effect of fermentation by mixed cultures of lactic acid bacteria on the $\mathrm{HCl}$-extractability of some minerals from tef (Eragrotis tef) atmit. Ethiopian J Sci 21: 183-194.

25. Kebede A, Fekadu B, Langsrud T, Narvhus J (2002) Parameters of processing and microbial changes during fermentation of borde, a traditional Ethiopian beverage. African J Food Tech 7: 85-92.
26. Mukisa IM (2012) Sensory characteristics microbial diversity and starter culture development for Obushera, a traditional cereal fermented beverage from Uganda.

27. Mugula JK, Nnko SM, Narvuhus JA, Sorhaug T (2003) Use of starter cultures of lactic acid bacteria and yeasts in the preparation of togwa, a Tanzanian fermented food. Int J Food Microbiol 83: 307-318.

28. Newell GJ, Macfarlane JD (1987) Expanded tables for multiple comparison procedures in the analysis of ranked data. J Food Sci 52: 17-21.

29. Muyanja CK, Narvhus JA, Treimo J, Langsrud T (2000) Isolation, characterization and identification of lactic acid bacteria from bushera: A Ugandan traditional fermented beverage. Int J Food Microbiol 80: 201-210.

30. Svanberg U, Sjögren E, Lorri W, Svennerholm AM, Kaijser B (1992) Inhibited growth of common enteropathogenic bacteria in lactic-fermented cereal gruels. World J Microbiol Biotechnol 8: 601-606. 